\title{
Recording of bioelectrical activity changes in sheep cerebral cortex
}

\author{
Registro de cambios en la actividad bioeléctrica de la corteza cerebral de ovejas \\ P Cwynar ${ }^{a, b^{*}}$, W Zawadzki ${ }^{a}$ \\ aDepartment of Animal Physiology, The Faculty of Veterinary Medicine, \\ Wroclaw University of Environmental and Life Sciences, Wroclaw, Poland. \\ ${ }^{b}$ Department of Environmental Hygiene and Animal Welfare, The Faculty of Biology and Animal \\ Science, Wroclaw University of Environmental and Life Sciences, Wroclaw, Poland.
}

\begin{abstract}
RESUMEN
El objetivo de este estudio es presentar el uso práctico de la electroencefalografía (EEG), demostrando el aspecto básico de EEG en ovejas, así como su utilidad en el análisis de las alteraciones provenientes del sistema nervioso central. Se examinaron 10 hembras híbridas de Oveja Merino Polaca, seleccionadas especialmente con fines experimentales. Debido a la falta de una fórmula unificada en el método de EEG en animales, se realizó un registro de potenciales provenientes de algunos puntos escogidos tras el experimento en cabezas de animales. Durante los experimentos realizados se demostró que la corteza cerebral de ovejas se caracteriza por una dinámica muy alta, hecho que fue demostrado al examinar las reacciones del sistema nervioso central a los factores tales como: el hambre, la estimulación auditiva o la inyección de xylazyna. La corteza cerebral de ovejas en el estado de reposo muestra una actividad bioeléctrica de una amplitud media de $30 \mu \mathrm{V}$ y una frecuencia de $25 \mathrm{~Hz}$, con lo cual se confirma la existencia del ritmo beta [ $\beta$ ]. La aplicación de un estímulo acústico permite estimular el sistema nervioso central de oveja, lo que queda comprobado por una elevación de la amplitud media (por 23\%) y de la frecuencia (por 21\%) de la actividad bioeléctrica de la corteza cerebral, como también lo confirma el electroencefalograma conseguido. Los datos obtenidos demuestran que la zona que se caracteriza por tener el tiempo más corto de reacción es la zona del mesencéfalo, con un tiempo medio de reacción de 0,56 segundos $( \pm 0,005 \mathrm{~s})$. Se discute además la aplicabilidad de los experimentos, así como también la posibilidad de unificar el método de EEG.
\end{abstract}

Key words: electroencephalography, sheep, cerebral cortex.

Palabras clave: electroencefalografía, ovejas, corteza cerebral.

\section{INTRODUCTION}

The dynamic development of medicine and its related disciplines have opened up the possibility of increasingly precise techniques for the monitoring of changes in the CNS, which is undoubtedly one of the most important parts of the organism in mammals.

An electroencephalographic examination is a method that summarizes the electric activity generated by neurons of the cerebral cortex (Eckhorn et al 1993, Aurlien et al 1999, Pellegrino et al 2004). It can be used used when collecting and recording the activity of the CNS and also in the analysis of its basic functions (Herin et al 1968, Goldman et al 2000). The procedure was introduced into general use during the 1950's, and until today it is characterized by its high precision and usefulness, especially in the research concerning brain activity (Jus et al 1954, Cwynar et al 2006). Unfortunately, due to its specificity, the method requires specialist research equipment. However, it should

Accepted: 04.11.2009.

* ul. Norwida 25/27, 50-375 Wroclaw, Poland; przemyslaw-cwynar@ wp.pl be emphasized that the use of electroencephalography in animals is hardly found in the available literature, because the subject is usually revised from point of view of human electrophysiology, so the data concerning the particular research may be found only in a few papers. The aim of this study was to record the bioelectrical activity of sheep cerebral cortex in three different stages: under the influence of hunger, sonic effect and xylazine. All of the procedures were registered with high precision in a digital form by the EEG equipment.

\section{MATERIAL AND METHODS}

The animals used in this study belonged to the Wrocław University of Environmental and Life Sciences, where they were kept in a vivarium. For the purposes of the experiment, the sheep were moved to the Department of Animal Physiology, which is equipped with its own vivarium. The experiment was conducted in this Department. Additionally, another room was adapted for experimental purposes and provided with hardware, research equipment and wooden, openwork cages. The experimental protocols were reviewed and accepted by the Animal Care and Use Committee. 


\section{CHARACTERISTICS OF EXPERIMENTAL ANIMALS}

The research was conducted on hybrids of Polish Merino sheep. Ten ewes aged 36-50 months, $40-45 \mathrm{~kg}$ body weight (eight for the active experiment, two as control test), were selected. According to Nowicki et al 2001, these individuals have the densest fleece per $1 \mathrm{~cm}^{2}$ within the whole species. These animals are characterized by a very thin diameter of fibre, ranging from 22 to $26 \mu \mathrm{m}$. This trait, as well as their quickly growing back wool, made it necessary to shave the sheep's heads before each experiment. Loose skin that does not cling to internal tissues is a great advantage in the animals choice for experiments with the use of EEG, which is also confirmed by the above-mentioned authors. It appeared to be the perfect surface for electrodes installation.

The highly developed herd instinct of sheep was taken into consideration in the present research. Two cages were placed in the laboratory, one for an experimental animal and a second one for an accompanying one. The high stress tolerance showed by these sheep hybrids was one of the reasons for choosing them as experimental animals. The sheep are also characterized by a gentle nature, which was added merit for their use in this research.

\section{RECORDING OF BIOELECTRICAL ACTIVITY IN THE CEREBRAL CORTEX}

The recording of the bioelectrical activity in cerebral cortex was carried out on the surface of the head by using disposable lamellar electrodes - EKG/ECG electrodes Ag/ $\mathrm{AgCl}$ (Lead-Lok, Poland). Each electrode was equipped with a capsule containing solid conductive gel. In order to obtain a proper record, it was crucial that none of the electrodes exceeded the resistance of $5 \mathrm{kOhm}$. The unipolar method was applied, where electrodes were permanently attached with a weld connected with a screened high conduction cable in order to avoid a negative influence of unessential waves and electromagnetic fields. The cable was joined to bridge amplifiers Bridge Amp (AD Instruments, Australia), and finally to a four-channel system for data canvassing PowerLab/400 (AD Instruments, Australia). Data was registered on a computer using Chart 4 for Windows v.4.2. software (PowerLab, AD Instruments, Australia) for the recording, reproduction and analysis of the information. This is an ergonomic way of applying electroencephalographic methods in animals research (i.e. without using large equipment). All records were registered with high precision in a digital form that enables their quick reproduction, retrieval of desired EEG fragments and their free modification during analysis.An uniform microvolt $(\mu \mathrm{V})$ scale (range $-100 ; 0 ; 100)$ was established in each of the four channels. Additionally, supplementary logic channels indicating the frequency of collecting impulses occurrence, were assigned to particular channels. The sampling rate was formulated at a level of 100 samples per second [100/s].
Simultaneously, the filter configuration was programmed. Therefore, resistance - capacitive circuits were activated by setting up low-pass (high-frequency) filters at a level of $60 \mathrm{~Hz}$, and a one-second time constant for high-pass filters attenuating the signals of low frequencies.

\section{PREPARATION OF EXPERIMENTAL ANIMALS}

Selected ewes were examined by a veterinarian in order to check their health status and to determine their usefulness for the research. During the electroencephalographic analysis, each sheep was in anestrum which except for the breed, age and weight similarity, aimed at the additional unification of an analyzed group. Two days before an experiment, sheep were introduced to the room where the brain activity was going to be recorded, in order to familiarise the animals to their new environment, and to prevent sudden experiences resulting from a lack of acclimatization. A constant temperature $\left(16-18^{\circ} \mathrm{C}\right)$ and free access to water were provided. Food rations were given in determined quantities, except during the last 24 hours before analysis, when the feeding stopped. The supervision, feeding, administration and caring activities were carried out by permanent workers.

\section{CONTROL TESTS}

At the beginning of the experiment, a square test was the first to be conducted in order to ensure a correct equipment functioning. The calibration of the appliances was done automatically. A control test had been conducted before the recording of cerebral cortex activity in order to check the reliability of the implemented experimental procedures and their possible verification. To achieve this, a solution of xylazine (2\% Rompun preparation, Bayer) was injected intravenously to a sheep, the doses of the applied pharmaceutical preparation were experimentally established at a level of $0.01 \mathrm{mg} / 1 \mathrm{~kg}$ of body weight. This amount induced a sedative effect on the nervous system and without posing a threat to the health of the animals. The application of the control method with analytical encephalographic techniques is considered essential.

\section{EXPERIMENT DESIGN}

The intravital method was used in this research, and it does not require the use of sedation. During the main part of the experiment, no pharmacological agents were given. A sheep was introduced into a purpose-built wooden cage and electrodes were applied on the skin of the animal's head after its previous shaving. That treatment enabled the total removal of fleece from a neurocranium area, affecting the frontal bone (os frontale), through the region of temporal (os temporale dextrum et sinistrum) and parietal bones (os parietale dextrum et sinistrum), to an area of occipital bone (os occipitale). Additionally, the hair rarely 
covering an area of the ethmoid bone (os ethmoidale) was removed. The skin was rinsed with $98 \%$ alcohol to eliminate vegetative forms of microorganisms living on the epidermis and dermis, to remove hair residues and to degrease the skin surface.

The primary needle electrodes, which were connected to the offtake cable with a tin weld, were used in the experiments. With regards to animal welfare, disposable lamellar electrodes made of stainless steel and covered with selfconducting gel were applied during this time-consuming research (lasting about 5 hours in total), to avoid animal suffering and discomfort and undesirable artifacts on the experiment. To prevent the electrodes from unsticking as a result of animal movements, the head was wrapped with an elastic bandage to increase the recording accuracy. Also, additional gel made up for EKG/EEG diagnostic purposes was applied to enable undisturbed transfer of a bioelectric stimulus between skin surface and an electrode. Impulses collected by silver electrode plates were transferred onto a computer.

An analogical technique of registering was used during the experiments. Four positive electrodes (marked as: 1a, 2a, 3a, 4a) were used to ensure reliable results, and an earthing of each of them (negative - 1b, 2b, 3b, 4b), integrated in one electrode (figure 1).

The connections used were the following:

1a) -forebrain, frontal bone (os frontale), left side;

2a) -forebrain, frontal bone (os frontale), right side;

3a) -midbrain (mesencephalon), central;

4a) -hindbrain (metencephalon), occipital area, central; 1-4b) -nose, area of ethmoid bone (os ethmoidale);

The main objective of the research included obtaining a record of a spontaneous activity of the cerebral cortex in sheep, lasting a minimum of 150 minutes, in order to develop a clinical protocol of EEG. Initially, the registration was conducted without human presence to guarantee the most comfortable conditions for the examined group of animals. Later, a similar record was conducted in the presence of the people who were carrying out the experiment, also during a minimum of 150 minutes, to add disturbance factors. The analysis of the chosen factors from the obtained data was carried out, in order to increase the accuracy of the CNS activity of the group of examined animals was a next step.

\section{DATA ANALYSIS AND A STATISTICAL ANALYSIS OF THE RESULTS}

As a result of the conducted research, multi-hours digital electroencephalographic records were obtained. Data was analised with an "off-line" method using Chart 4 for Windows v.4.2 software (AD Instruments, Australia with Windows XP operating system. A comparative analysis of the results obtained from particular samples

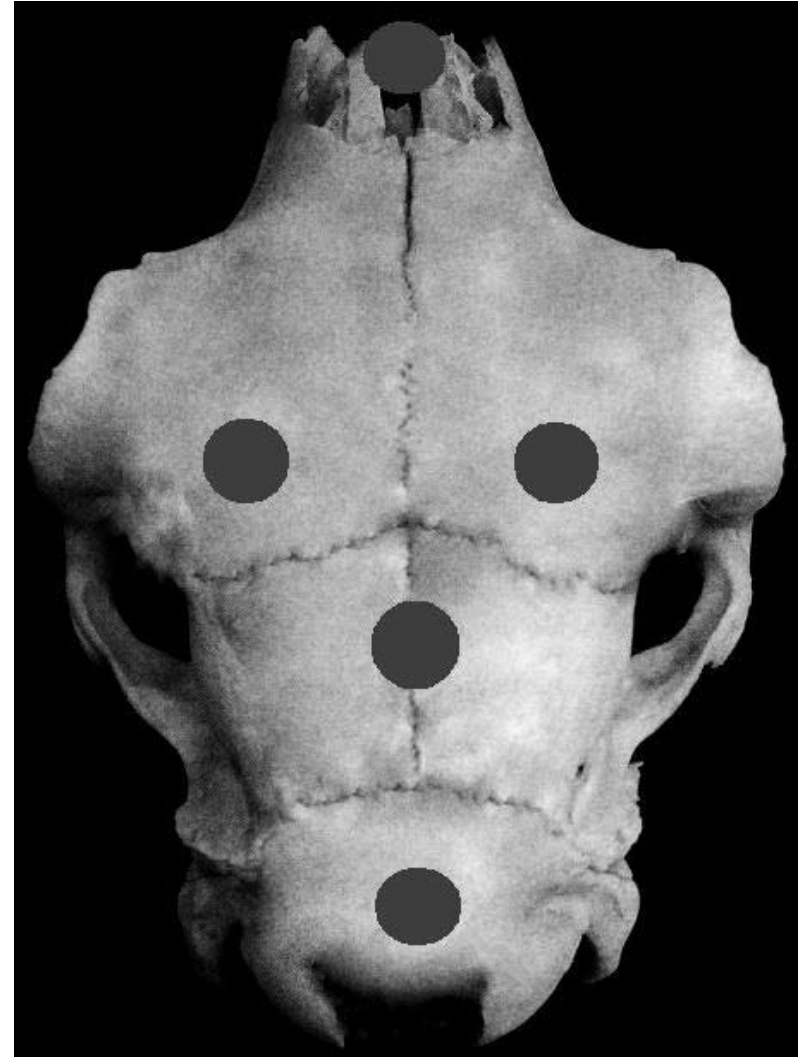

Figure 1. Main points for EEG recording in sheep.

Puntos principales para registrar la actividad bioeléctrica en la corteza cerebral de oveja.

and index values within the analyzed group of animals, was carried out. Also, the number of needle potentials in each record and the time interval they occurred in, were taken into consideration for the calculations. The relations between obtained amplitudes and frequency of an electrical impulse occurrence were also carefully examined. The values of the bioelectrical activity in the cerebral cortex were determined experimentally during the conducted procedures, and they were accepted as correct. This was based on the examination of 10 sheep and conducting a total of 30 analyses. Arithmetic means for minimal and maximum values were calculated from the obtained results. The physiological standard was accepted, based on the detailed examination of registered changes in bioelectrical parameters of the central nervous system, and it had to be established due to the lack of unification in the available literature. The results represent the effect of long-lasting experiments based on 30 examinations, and were analyzed by using mean values with specification of standard deviation and standard error ( $\bar{X} \pm$ SEM). A multifactor analysis of variance (ANOVA) and Student's t-test were used to compare mean values in experimental and control groups. Differences between experimental and control groups were significant $(\mathrm{P}<0.05)$. 


\section{RESULTS}

INFLUENCE OF XYLAZINE ON THE BIOELECTRIC ACTIVITY OF THE SHEEP CEREBRAL CORTEX

Electrical impulses of small amplitudes and various frequencies were obtained from the sheep connected to the research device. Numerous electrical impulses and groups of needle potentials sometimes reaching up to $200 \mu \mathrm{V}$ were determined. An intravenous injection of xylazine (2\% Rompun preparation, Bayer) was applied to verify whether the obtained results originate from cortical centers of the nervous system. The dose (determined experimentally) calmed down the rhythm of registering waves about 2 minutes after application. Figure 2 shows the sample registration of biological activity of the cerebral cortex after the xylazine injection. Standardization of the record lasted up to 3 hours from the medicament administration. Once the action of the pharmaceutical agent blocking inter-neuronal transmission had finished, the electroencephalographic picture returned to its original form. During the 4 following days of xylazine (2\% Rompun preparation Bayer) administration, reactions of the sheep central nervous system remained at a similar level (no statistically significant differences were observed). During the next trial, on the 5th day, a decrease in the reaction towards the given medication was noted.

\section{BIOELECTRICAL ACTIVITY OF THE SHEEP CEREBRAL CORTEX IN A NORMAL STATE}

An attempt of registration of the electrical impulses coming from the CNS and determination of their frequency degree were undertaken during the research. The research was also conducted in stress-free conditions as shown in figure 2. Measurements were done with a time accuracy of up to 0.2 second $( \pm 0.025 \mathrm{~s})$. The mean value of voltage was $26.5 \mu \mathrm{V}$ in channel 1, which is an offtake from a left frontal bone area. An assigned logical channel analysing the frequency of electrical impulses revealed the

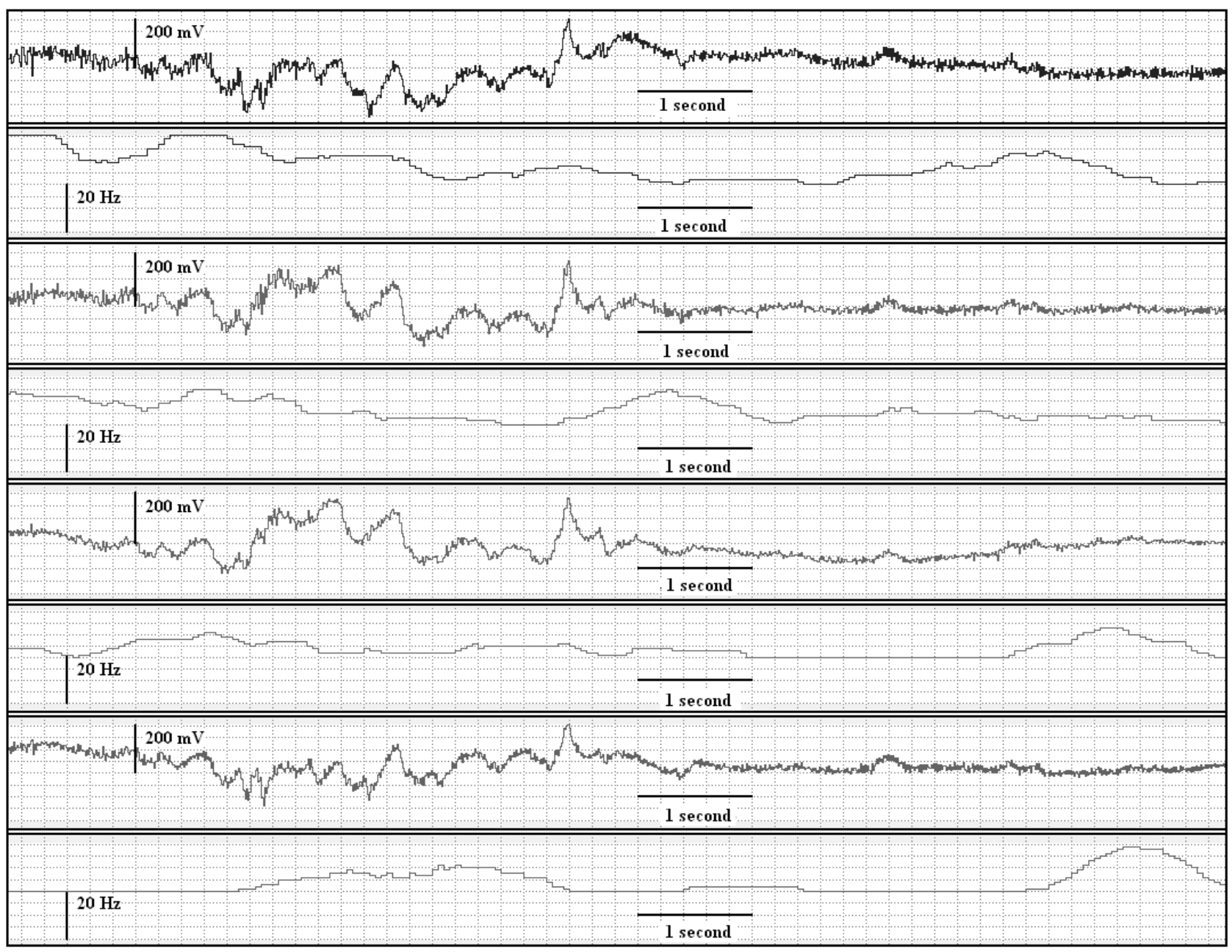

Figure 2. Sample registration of a biological activity of an the cerebral cortex of an adult sheep after the xylazine injection. Muestra de registro de la actividad bioeléctrica en la corteza cerebral de una oveja adulta después de la inyección con xylazina. 
occurrence of approximately 23 cycles during 1 second $(23 \mathrm{~Hz}$ ). Localization of the electrodes of channel 3 (os frontale dextrum) together with channel 4 determined the voltage level of a mean value of $25.2 \mu \mathrm{V}$, and impulses frequency at a level of $24 \mathrm{~Hz}$. From the results obtained from the area of frontal bones, it can be concluded that a relatively high degree of similarity between registered rhythms of the central nervous system was found. The cerebral cortex waves registered in the mesencephalon region reached mean values at a level of $22.5 \mu \mathrm{V}$, and a number of cycles were at a level of $28 \mathrm{~Hz}$. During the registration, sparse, single groups of needle potentials were observed in the midbrain area and also a relatively higher kind of frequency when compared to other zones, reaching up to $36 \mathrm{~Hz}$ (figure 3, channel 6). Channels 7 and 8 summarized the bioelectrical activity of the brain in the metencephalon area. In the first offtake a voltage of $18 \mu \mathrm{V}$ was noted, while in the second one, the mean number of cycles reached $26 \mathrm{~Hz}$. Therefore, the results had statistically significant differences, since the offtakes from the frontal bones differ by $4.9 \%$ with an analysis of bioelectrical voltage of the cortical centers and a frequency level of $4.1 \%$. It was also pointed out that the mean values obtained from the midbrain were higher than the mean of records originating from the hindbrain region and were in a category of $20 \%$ of the voltage difference, also the impulses frequency was $27 \%$ higher. The range of waves of the cerebral cortex bioelectrical activity allow to classify the discussed changes as a typical beta rhythm $[\beta]$.

\section{INFLUENCE OF EXPERIMENTAL STARVATION ON THE BIOELECTRICAL ACTIVITY OF THE SHEEP CEREBRAL CORTEX}

One stage of the conducted experiments consisted in withdrawing the food from the analysed group of animals during the 24 hours before trial, in order to determine the influence of the hypothalamus reaction on the general bioelectrical mechanisms of the central nervous system (figure 5), and also an influence of selective feed providing.

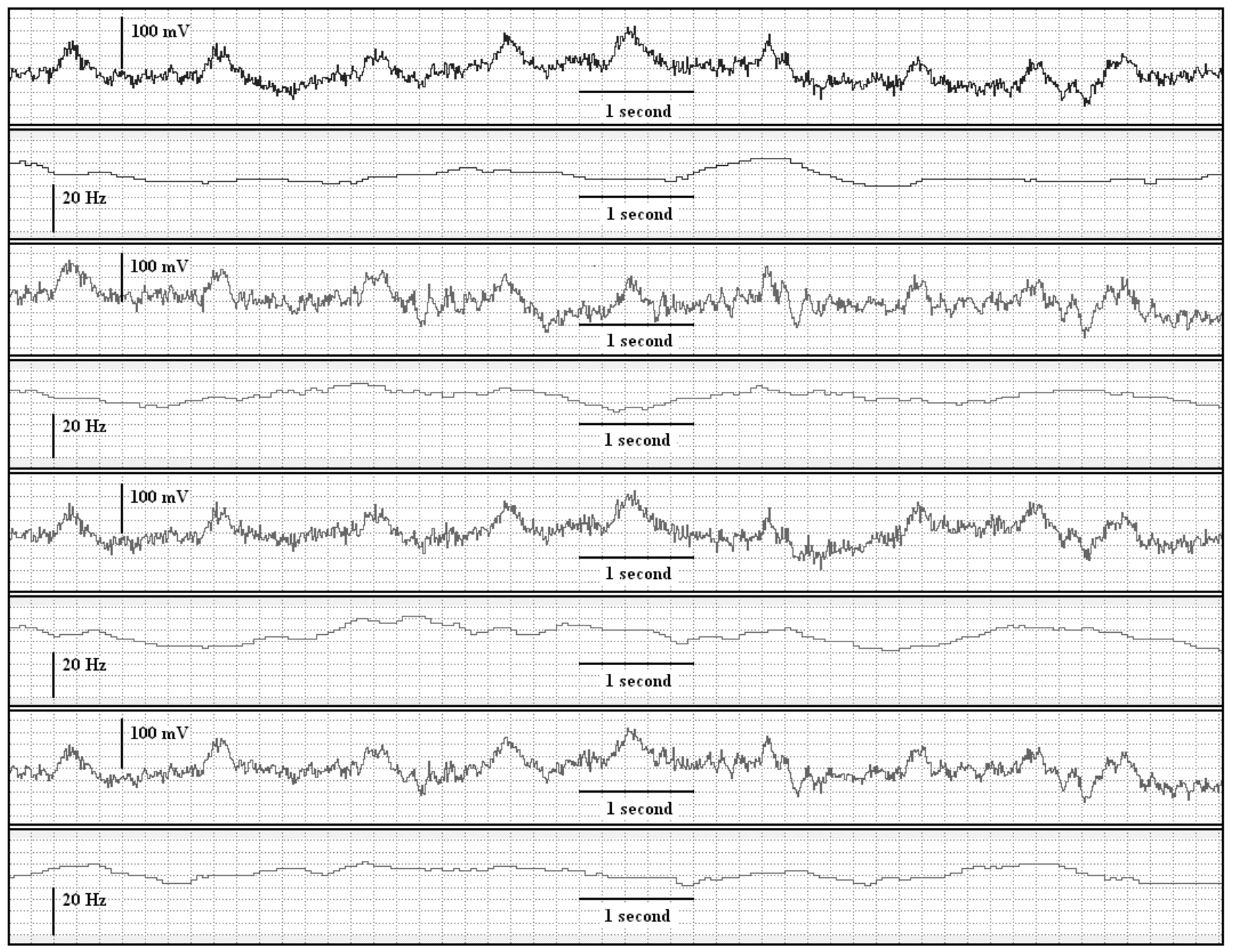

Figure 3. Sample electroencephalogram from an adult sheep obtained in a resting state.

Muestra de electroencefalograma de una oveja adulta en estado de reposo. 
During the conducted experiment, a time accuracy of up to 0.2 seconds $( \pm 0.025 \mathrm{~s})$ was used. Data obtained from channel 1 analysed, obtaining mean values of bioelectrical voltage of $24 \mu \mathrm{V}$, while in channel 2 , they reached $21 \mathrm{~Hz}$. Comparable average information was maintained in the offtakes from an area of the os frontale dextrum and totalling $28 \mu \mathrm{V}$ together with the number of cycles at a level of $28 \mathrm{~Hz}$. Sparse frequencies of impulses reaching up to $31 \mathrm{~Hz}$ were also collected from that area of the skull. The region of the mesencephalon generated mean potentials of $26 \mu \mathrm{V}$ and the addition of cycles per second reached even 40; additionally, that rhythm was often maintained for a period of up to 1.6 seconds $( \pm 0.025 \mathrm{~s})$. It was the highest statistically significant response of the central nervous system to starvation and, moreover, the most significant difference in the experiments conducted so far. Similar values were obtained also from the region of the metencephalon. However, the mean obtained values did not exceed $32 \mathrm{~Hz}$, and their bioelectrical voltage was not higher than 15. In spite of existing differences from the particular offtakes, the results obtained allow to classify the described waves as beta rhythm $[\beta]$. It should be pointed out that the mean values of cortical potentials are within the range of accepted electroencephalographic standards, however, the estimated frequency presents higher fluctuations of terminal values within the records than the values described in the available literature.

\section{INFLUENCE OF A SOUND STIMULUS ON THE BIOELECTRICAL ACTIVITY OF SHEEP CEREBRAL CORTEX}

A procedure for the application of a uniform sonic stimulus was implemented for all individuals in the analysed group. At the first stage of the experiment, the timbre of the introduced impulse was not known to any of the sheep, resulting in a spontaneous reaction of the cerebral cortex (figure 3). After the sound emission, the immediate reaction of the nervous system was observed. The offtake of channel 1 exhibited the reaction to the sonic impulse by an increase in voltage to a mean value of $28 \mu \mathrm{V}$, while in an interval of 0.14 seconds $( \pm 0.005 \mathrm{~s})$ a sudden decrease in cortical bioelectrical voltage manifested by a needle stage of a mean value of $-122 \mu \mathrm{V}$, was noted. During the next stage, there was a return of potentials to the initial positive values specified by a mean of $132 \mu \mathrm{V}$ and a renewed decrease to - $48 \mu \mathrm{V}$. An assigned logical channel analyzing the frequency of impulses pointed out the number of 25 cycles per minute at an initial stage of the stimulus application and ended with a value of $27 \mathrm{~Hz}$. During the first phase of CNS response, channel 3 clearly pointed out an increase in potential of up to $50 \mu \mathrm{V}$, rapidly reaching a mean at a level of $-140 \mu \mathrm{V}$. In the last stage, as in the case of an area of the os frontale sinistrum, the return to positive potential at a level of $125 \mu \mathrm{V}$ and a renewed decrease to a mean value of $-26 \mu \mathrm{V}$ were noted. Registered changes in the bioelectrical activity of the cerebral cortex from the midbrain area were the most determined reaction of cortical centers to the applied sonic stimulus. It was manifested by a preliminary phase of a short and also intense group of needle potentials reaching $60 \mu \mathrm{V}$, and usually one or two needle deformations after that, which brought the electroencephalogram to negative transition potentials reaching a level of even $-142 \mu \mathrm{V}$. The time of needle wave reflection lasted 0.11 seconds $( \pm 0.015 \mathrm{~s})$ on average. In the next stage, there was a return to a positive potential, which was $138 \mu \mathrm{V}$ on average. The last phase of the reaction to the stimulus was its normalization, with a decrease in cortical voltage by $94 \mu \mathrm{V}$ on average (figure 4 ).

It was observed during the experiment that in a logical offtake of channel 5, the frequency of bioelectrical potentials during the signaling of a sonic stimulus always tended to decrease. The first stage of a response of this part of CNS centers to the stimulus was characterised by a mean frequency of $38 \mathrm{~Hz}$.

At the moment of needle potential reflection, a change of the previous value to the number of 30 periods per second was observed. In the last phase (the return to a positive potential), the frequency was just $26 \mathrm{~Hz}$.

Compared to the midbrain response of the cerebral cortex, a relatively weaker response was observed in the area of the metencephalon. The appearance of single needle potentials was maintained but they were characterised by a smaller voltage reaching terminal values at level -122 (minimum) and 128 (maximum) $\mu \mathrm{V}$. A declining tendency of frequency was also maintained, however, to a relatively smaller degree. It was $34 \mathrm{~Hz}$ in an initial phase of the stimulation, through the number of 29 periods per second during the reflection of needle potential, to the level of $28 \mathrm{~Hz}$ at the end.

It should be mentioned that the reaction time of each of the channels was not uniform. In the course of the experiment, detailed measurements of the time of reaction to the stimulus in the particular offtakes were conducted. The area of the mesencephalon is characterised by the shortest time of response to a stimulus, reaching an average result of 0.56 seconds $( \pm 0.005 \mathrm{~s})$. The second in a sequence is an area of the metencephalon with a mean reaction time of 0.62 seconds $( \pm 0.005 \mathrm{~s})$. The average results obtained, indicated that the right frontal bone area exhibited the longest time of reaction to the sonic impulse, reaching 0.66 seconds ( $\pm 0.005 \mathrm{~s})$, while an adjacent canal carrying off the record from the left frontal bone responded in the time of 0.64 seconds $( \pm 0.005 \mathrm{~s})$. The previously mentioned results were compared with an experiment conducted on resting sheep. It was observed that the $o$ s frontale sinistrum region exhibited an amplitude $38 \%$ lower than the one mentioned in the experiment (with the frequency deviation of $13 \%$ ), while the region of $o s$ frontale dextrum increased the value of the potentials induced also to $38 \%$ and $13 \%$ of the cyclic discrepancy. The area of the mesencephalon showed the highest increase in bioelectrical voltage reaching $48 \%$, with $35 \%$ 


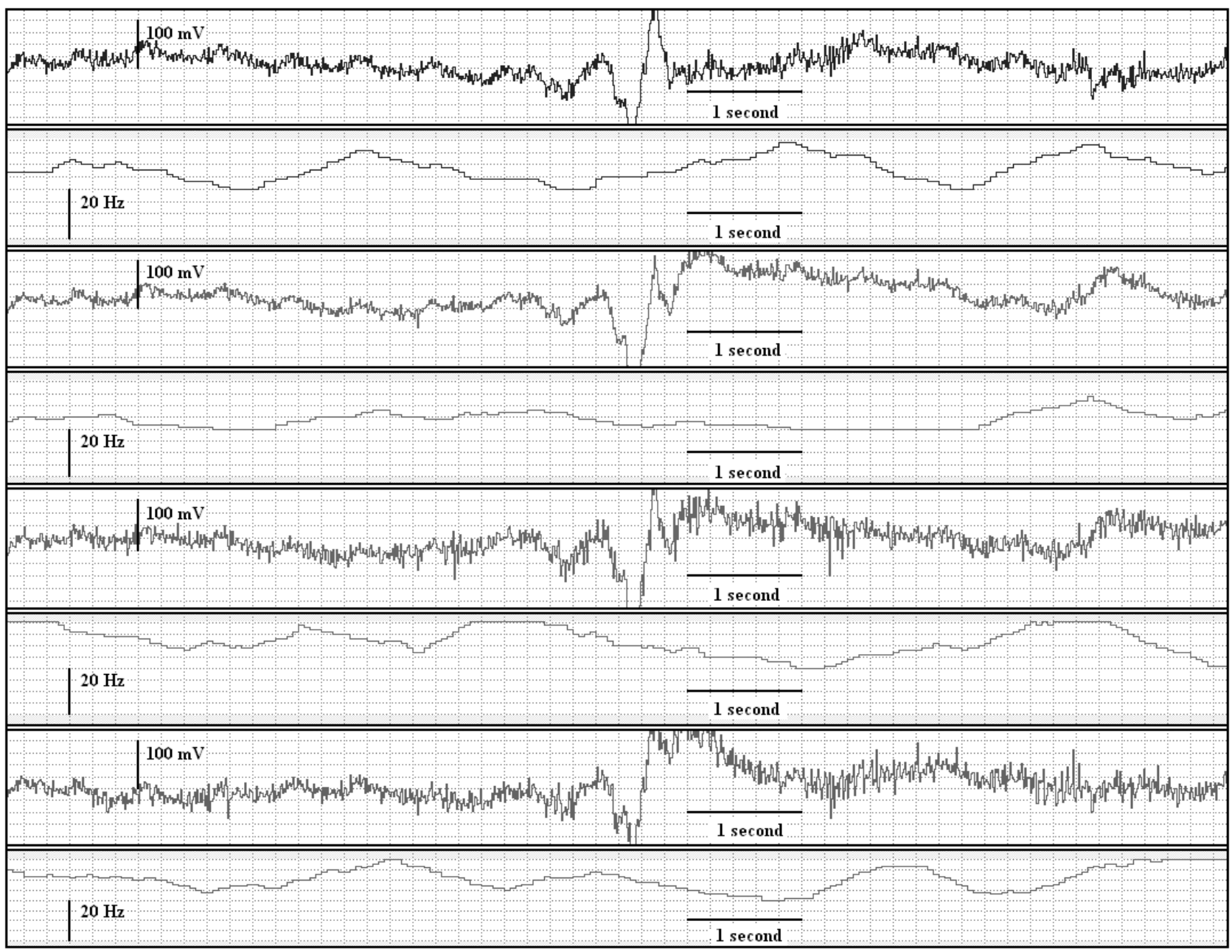

Figure 4. Sample record of changes in adult sheep cerebral cortex activity under the influence of a sound stimulus.

Muestra de registro de las alteraciones de la actividad bioeléctrica de la corteza cerebral de ovejas sometidas a la estimulación auditiva.

of difference in frequency. Relatively lower activation - of $44 \%$ and $23 \%$ of the cyclic discrepancy, was noted in the metencephalon area. After the assessment of differences in both experiments, statistically significant divergencies between these experiments were stated.

\section{INFLUENCE OF FEEDING ON THE BIOELECTRICAL ACTIVITY OF SHEEP CEREBRAL CORTEX}

The registration of bioelectrical potentials of the cerebral cortex as a result of the excitement caused by providing food after the starvation period, and hunger satisfaction itself, was also carried out. The results showed changes in data registering, and also some degree of similarity of the cortical potentials values (figure 3). It was observed that the offtake from the left frontal bone area indicated the initial bioelectrical activity at a level of $-50 \mu \mathrm{V}$, and then it increased to a mean value of $77 \mu \mathrm{V}$. The next element of a wave is a voltage decrease to a mean of $-77 \mu \mathrm{V}$ with clearly marked incident of a single (sporadically double) needle potential. The amplitude of potentials of that offtake was assessed during the experiment; it oscillated in a range of $145 \mu \mathrm{V}( \pm 7 \mu \mathrm{V})$ while the frequency ranged from 22 to $38 \mathrm{~Hz}$. A similar tendency was found when comparing the above-mentioned data with a result of an experiment from the os frontale dextrum area, however the values differed from the previous ones. The bioelectrical potential started from a mean value of $-10 \mu \mathrm{V}$, then it reached $+52 \mu \mathrm{V}$, and finally it decreased by the specified needle to the value of $-72 \mu \mathrm{V}$. It was observed at the same time that the electroencephalogram periodicity was almost identical in the first channel, as in the third one, since in the last of them it resulted in receiving a range of $23-38 \mathrm{~Hz}$. It should be pointed out that the amplitude of potentials was at a level of $154 \mu \mathrm{V}$. The biggest fluctuations were observed in the mesencephalon, where the values reached $228 \mu \mathrm{V}$. Nevertheless, the records differed from the previous ones in the occurrence of three, and in some cases even four, distinct needle rhythms. The magnitude of potentials was subject to deviations of 50 on average, and even $75 \mu \mathrm{V}$. Similar results were also observed in the area of the metencephalon. Periodicity of the bioelectrical impulses 
of both offtakes (5 and 7) oscillated within the range of (23-40) Hz. Non-uniform periods between consecutive wave rhythms in each of the channels were also noticed. For the region of the frontal bone, they were 0.82 seconds (left part), 0.74 seconds (right part), respectively, with the measurement of time accuracy at a level of \pm 0.005 seconds. The shortest biopotential persistence was reported for the midbrain, with a mean time of 0.72 seconds, and a part of the hindbrain that reached the value of 0.74 seconds $( \pm 0.005 \mathrm{~s})$.

\section{DISCUSSION}

The objective of the present work was to demonstrate the electrical activity of the central nervous system, and the influence of the applied experimental procedures on the occurring changes. The subject of the electroencephalographic methodology applied to the animals is rather sporadically raised in the available neurophysiologic literature. The problems are characterised by an extraordinary rarity of their raising. In spite of that, the developing of medical sciences together with the diseases originated in the CNS (e.g. encephalitis, epilepsy, neuropathy), are a call for the creation of research procedures that allow a quick and precise diagnosis of these pathologies in animals.

\section{ELECTROENCEPHALOGRAPHY APPLICATION IN THE RESEARCH ON THE CENTRAL NERVOUS SYSTEM}

According to Mahl (1997), an electronic system of data collection is essential to achieve accurate results considering that each of the channels archives data came from two different electrodes. It is only possible to create a real electroencephalogram on the basis of the synthesis and conversion of these two records (Vaughan et al 1998). According to Reardon et al (1999), the detection of anomalies present (e.g. epileptogenic focuses) in the cerebral cortex with the use of EEG apparatus may last even 15 minutes, making it an unusually quick, effective, and, first of all, reliable method. It is also confirmed by Goodin and Aminoff (1984) and other authors who currently use these procedures (American Electroencephalographic Society I/1994, XIV/1994, De Luca 1998, Nuwer 2003) who distinctly emphasize that the significance of the electroencephalogram in recognition of a disease focused on the neurological basis. The selection of animals for the experimental procedures with the EEG apparatus depends mainly on their conformation, breed and individual factors. The use of sheep for this experiment was based not only on the facilities provided by the Department of Animal Physiology, but also on the easy maintenace of the animals and their calm nature. The available literature on this subject does not indicate a uniform animal model, moreover, they recommend diversity. In spite of that, frequently used animals for this kind of procedures are canidae (Pampiglione 1963, Herin 1968, Susuki et al 1985, Pellegrino et al 1997 ,
Ives et al 2006), felidae (Yamaguchi 2000), and pigs (Saito et al 2005). Rodents are often used, such as mice (Weiergräber et al 2005), rats (Ichinoze et al 1999, Kayama 2003, Kowalczyk et al 2004, Ashequr et al 2005) or guinea pigs (Mumford et al 2001). Numerous authors recommend the EEG examination together with alternative methods (MEG, MRI, PET, etc.), which allows a thorough analysis of the processes and phenomena in the CNS (Zadra et al 1998, Konareva 2005). Yoshinaga et al (2002), referring to practices of Cohen et al (1990) and Homma et al (1994), advise the application of the electroencephalographic apparatus consolidated with magnetoencephalography, defining this as the most useful combination out of all the diagnostic techniques available in neurophysiology. This opinion is also shared by Wolpaw et al (2002), Otsubo et al (2004) and LeVan et al (2006). However, according to Zadra et al (1998) a system of topographical mapping of CNS structures is a reliable examination. Goldman et al (2000) recommended the introduction of the simultaneous EEG recording combined with a spectroscopic examination. The "neurofeedback" practice based on digital EEG records is also of common use, its technology allows the autoregulation of physiological mechanisms of the cortical centers (Dzhunusova et al 2002, Konareva 2005). According to many researchers, the electroencephalogram is one of the most precise and complex sources of knowledge about the CNS in neurophysiological sciences (Nuncz 1981, Etevenon 1986, Boiten et al 1992, Aurlien et al 1999, Reardon et al 1999, Millett 2001, Rowan et al 2003, Razoumnikova 2003, Kaiser 2005). With regards to the reliability of the results obtained, the literature on the subject does not mention the unequivocal standardization of records for particular animal species, which may cause significant differences in the analysis and interpretation of the obtained data (Pellegrino and Sica 1997, Ives et al 2006). The contrasting role is undoubtedly played by the amount of electroencephalographic literature regarding that kind of examination in humans. Most of the technical aspects, such as electrodes localization, research apparatus used and ranges of particular brain waves are widely known and successfully used in practice (Lesser et al 1985, Butler 1987, Homan et al 1987, Rosenblatt et al 1999, Vock et al 2002, Danko et al 2002, Armitage et al 2003, Velis 2005). Despite the many different opinions of researchers, it is certain that the electroencephalographic diagnostic is regarded highly among neurophysiological examinations and may be successfully used, not only in humans but in animals as well.

Appropriate and correct functioning of the CNS is directly connected with all the factors influencing the undisturbed work of the whole organism. It should be stressed that there is a disagreement between the authors about the number of electrodes used in particular offtakes. Zadra et al (1998) suggest the arrangement of up to 19 electrodes, and this was strongly supported by Allen (2000) and Otsubo et al (2004), while Chang (2002) proposes the 


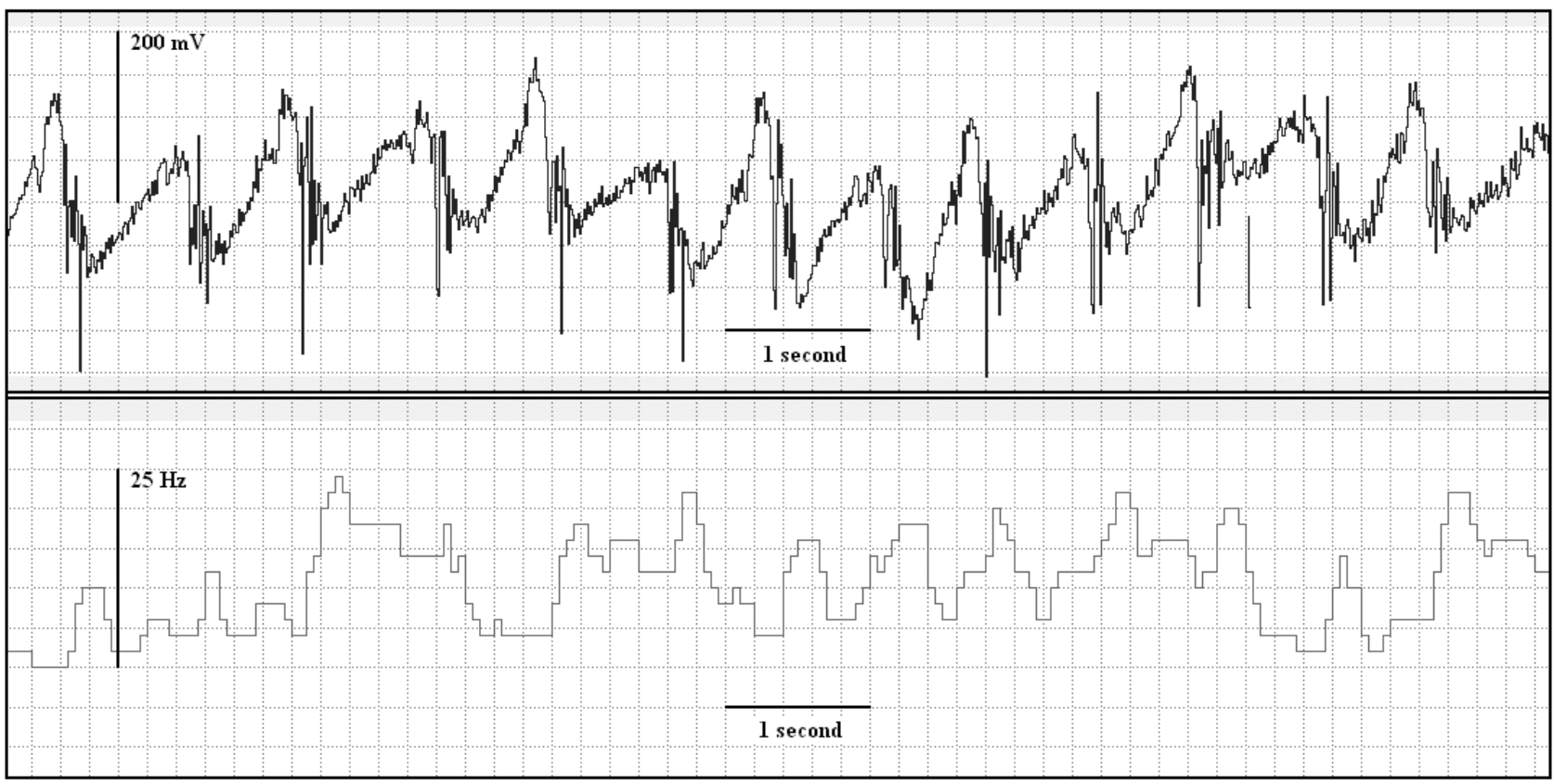

Figure 5. Fragment of the sheep electroencephalogram during hunger. The picture was additionally enlarged with the use of Chart 4 for Windows v.4.2. software. Visible needle potentials composed of a few peaks. This is a result of overlying of functional potentials created in adjacent cells for a similar time.

Fragmento de electroencefalograma de oveja en estado de privación alimenticia (hambre). La imagen fue aumentada gracias a Chart 4 for Windows v.4.2. Los potenciales afilados visibles compuestos de varios peaks como resultado de la sobreposición de los potenciales funcionales creados en células adyacentes en un tiempo similar.

application of a uniform number of 32 electrodes according to the commonly accepted international system $10-20$ (the 10- 20 International System of Electrodes Placement), which is also accepted by Homan et al (1987), Intriligator et al (1995) and Rowan et al (2004). A different opinion is expressed by Razoumnikova (2003) who claims that 16 electrodes introduced into the analysis is sufficient, in agreement with the theory of Liporace et al (1998), who applied a system in a 16-channel dimension. On the other hand, Mattia et al (2004) used 64 electrodes in their electroencephalographic practice, and modelled on the Gevins's methodology (1990), who used a 124-channel apparatus. In this experiment, a surface proportion of a human to sheep skull was taken into consideration when deciding the application of five electrodes in total, allowing to obtain an eight-channel system of data registration. A similar strategy was used by Saito et al (2005) in an experiment with pigs. It seems that the results obtained are reliable, that is why the procedure was not verified. The works by Weiergräber et al (2005), and also by Yoshida et al (2004), who used 3 electrodes in the case of rats, seem to confirm the above-mentioned opinion.

\section{DETERMINATION OF A NORMAL REACTION OF THE CEREBRAL CORTEX BIOELECTRICAL ACTIVITY IN SHEEP}

The EEG examination is based on an inter-neuronal information exchange, with a particular voltage and frequency of occurrence. Therefore, it may be unambiguously stated that occurring potentials correspond to the commonly accepted standards. In the case of humans, presently accepted standardization (Salansky et al 1998, Aurlien et al 1999, Finnerup et al 1999, Nishida 1999, Razoumnikova 2003, Rowan et al 2004, Marrosu et al 2005, LeVan et al 2006) allows to determine the neurophysiological state of a patient. The research is so advanced that, as it is suggested by Velis (2005), it is possible to determine the predispositions for a job performance on the basis of electroencephalogram. Unfortunately the technology and also the knowledge resulting from the research on animals are not as comprehensive. This is the result of a lack of unification of the species mentioned before. Thus, all analyses may only be based on the research on humans carried out until now, and map main threads just from that field. For that reason, some of the researchers (Ichinoze et al 1999, Pellegrino et al 2004) believe that such practice allows to uniform the analysis and interpretation of the obtained results. During the experimental procedures conducted in the present work, a standard of physiological record of the bioelectrical activity of the cerebral cortex was established individually for the sheep. Such a procedure is justified by the fact that each species of animals has its own features, while the available literature does not specify sheep as research objects in an electroencephalographic technique. Standardization of the EEG record to a smaller extent is accepted by other researchers (Mumford et al 
2001, Yoshida et al 2004, Weiergräber et al 2005, Ives et al 2006). They do not deny 10-20 system, however, they try to be more careful in its application among animal experimental methods.

The majority of authors try to support a compulsory convention of waves classification in frequency ranges, which took the attention of Jus et al (1954), Creutzfeldt et al (1966), Eckhorn (1993), Shimegi (1999), and also Wypych et al (2004). However, Saito et al (2005) give the ranges of rhythms of cortical origin according the following criteria: alpha waves $(\alpha)$ in a range $(8-12,9) \mathrm{Hz}$, beta $(\beta)$ in a range $(14,1-25\} \mathrm{Hz}$, theta $(\theta)$ in a range $(4-7,9)$ $\mathrm{Hz}$, and delta $(\delta)$ in a range $(1-3,9) \mathrm{Hz}$. Experiments conducted by these scientists with the use of the EEG apparatus on piglets, specify analogical ranges of rhythms to those determined during the research on sheep. It must be emphasized that this study was carried out when sheep had their eyes open, that is why the special consideration of beta waves was a basic aspect of the experiment. In the case of these animals, the examined beta waves $[\beta]$ seem to have significantly higher values than in the case of pigs or rats (Ichinoze et al 1999), reaching even up to $40 \mathrm{~Hz}$. It is important as the measurement can define, according to the criterion accepted before, a harmonious and proper reaction of the cerebral cortex, which is expressed by bioelectrical potentials. Pellegrino et al (2004) demonstrated that in dogs under the influence of xylazine, with closed eyelids (without any access of visual stimulus), alpha waves $(\alpha)$ are mainly present, as well as the waves of lower biopotentials voltage values, and also of lower frequencies. Unfortunately, there is a lack of the electroencephalographic experimental procedures concerning sheep in the available literature. According to Klass (1977), Kozelka et al (1990), Vaughan et al (1998), Goldman et al (2000) and Kalita et al (2006) the magnitudes of the rhythms of cortical origin, with special consideration given to the value of amplitude and its periodicity, are the basis for proper determination of brain bioelectrical activity, and are also connected with the precise definition of the physiological state of the CNS. This theory is supported by numerous authors (Chokroverty et al 1995, Intriligator et al 1995, Mahla 1997, Liporace et al 1998, Schack et al 1999, Goldman et al 2000, Wolpaw et al 2002, Armitage et al 2003, Ashequr et al 2005, LeVan et al 2006), and there are no studies challenging that theory.

In connection with the above, the waves detected during the experiments on sheep belonging to the beta rhythm $[\beta]$ may confirm the proper course of reaction in CNS and proper physiological processes in the cerebral cortex.

\section{SUMMARY}

The aim of the study was to present a practical application of electroencephalographic techniques. The essential aspects of EEG in sheep and its usefulness in the analysis of changes in the CNS, are demonstrated in the paper. The experiments were conducted on 10 ewes, hybrids of the Polish Merino, selected especially for laboratory purposes. There is no standard pattern in encephalographic methods in animals, that's why the authors made a registration of the induced biopotentials in sheep from the experimentally chosen points of the animals head. It was presented during the experiment that the cerebral cortex is characterized by a high dynamism index, which was proved during the experiments on CNS reactions to the factors such as hunger, sonic emission or control xylazine influence. The cerebral cortex of sheep in a vesting conditions reveals a bioelectric activity of a mean amplitude of $30 \mu \mathrm{V}$ and a frequency of $25 \mathrm{~Hz}$, which confirms existence of a beta $[\beta]$ rhythm. An application of a sonic stimulus enables the stimulation of the central nervous system of sheep, which is confirmed by an increased mean amplitude (of 23\%) and a frequency (of $21 \%$ ) of the cerebral cortex activity, and also by the electroencephalogram. Results obtained prove that the region of the mesencephalon is characterised by the shortest time of reaction to the introduced stimulus, and the mean time of response is 0.56 seconds $( \pm 0.005 \mathrm{~s})$. The ways of the most suitable practices as well as the chances for unification of EEG method were discussed.

\section{ACKNOWLEDGEMENTS}

The authors would like to thank the staff of the Animal Physiology Department of Wrocław University of Environmental and Life Sciences, specially Dr. Albert Czerski for his advice and help during the research.

\section{REFERENCES}

Allen PJ, O Josephs, R Turner. 2000. A method for removing imaging artifact from continuous EEG recorded during functional MRI. NeuroImage 12, 230-239.

American Electroencephalographic Society. 1994. Guideline Fourteen. Guideline for recording clinical EEG on digital media. J Clin Neurophysiol 11, 114-115.

American Electroencephalographic Society. 1994. Guideline One. Minimum technical requirements for performing clinical electroencephalography. J Clin Neurophysiol 11, 2-5.

Armitage R, M Husain, R Hoffman, AJ Rush. 2003. The effects of vagus nerve stimulation on sleep EEG in depression. A preliminary report. J Psychosom Res 54, 475-482.

Ashequr RMd, C Kamei. 2005. Electroencephalogram and behavioral changes induced by histamine applications into the nasal cavity and the effects of some $\mathrm{H}_{1}$-receptor antagonist. Int Immunopharmacol $5,1741-1748$

Aurlien H, IO Gjerde, NE Gilhus, OG Hovstad, B Karlsen, H Skeidsvoll. 1999. A new way of building a database of EEG findings. Clin Neurophysiol 110, 986-995.

Boiten F, J Sergeant, R Geuze. Eventrelated desynchronization: The effects of energetic and computational demands. Electroen Clin Neurophysiol 82, 302-309.

Butler PR. 1987. A Textbook of Clinical Neurophysiology. Wiley, Chichester, UK, Pp 9-20.

Chang PF, L Arendt-Nielsen, ACN Chen. 2002. Dynamic changes and spatial correlation of EEG activities during cold pressor test in man. Brain Res Bull 57, 667-675.

Chokroverty S, W Henig, D Wright, T Walczak, J Goldberg, R Burger, J Belsh, B Patel, S Shah, R Mero. 1995. Magnetic brain stimulation: safety studies. Electroen Clin Neurophysiol 97, 36-42.

Cohen D, BN Cuffin, K Yunokuchi, R Maniewski, C Purcell, GR Cosgrove, J Ives, JG Kennedy, DL Shomer. 1990. MEG versus EEG localization test using implanted sources in the human brain. Ann Neurol 28, 811-817.

Creutzfeldt OD, S Watanabe, HD Lux. 1966. Relations between EEG phenomena and potentials of single cortical cells. I. Evoked responses after thalamic and epicortical stimulation; Electroen Clin Neurophysiol 20, 1-18. 
Cwynar P, A Zawadzka. 2006. The electroencephalography against the background of chose contemporary methods serving to veryfy anatomical structures and functional ability of central nervous system in people and animals. Acta Sci Pol Medicina Veterinaria 5, 91-106.

Danko SG, NP Bechtereva, NV Shemyakina, LV Antonova. 2003. Electroencephalographic correlates of mental performance of emotional personal and scenic situations: I. Characteristic of local synchronization. Human Physiology (translated from Fiziologiya Cheloveka) 29, 263-272.

De Luca L. 1998. TeleEEG: A telemedical software pachage for EEG. Future Gener Comp Sy 14, 61- 66.

Dzhunusova GS, RA Kourmashev. 2002. Using adaptive EEG-biocontrol for correction of the functional state of neurological patients. Fiziologiya Chelovieka 28, 18-22.

Eckhorn R, A Obermueller. 1993. Single neurons are differently involved in stimulus-specific oscillations in cat visual cortex. Exp Brain Res 95, 177-182.

Etevenon P. 1985. Applications and perspectives of EEG cartography. Topographic mapping of brain activity. Butterworths, Boston, USA, Pp 113-141.

Finnerup NB, A Fuglsang-Frederiksen, P Røssel, P Jennum. 1999. A computer-based information system form epilepsy and electroencephalography. Int J Med Inform 55, 127-134.

Gevins A. 1990. Beyond topographic mapping: towards functionalanatomical imaging with 124-channel EEG and 3-D MRIs. Brain Topogr 1, 53-64.

Goldman RI, JM Stern, J Engel Jr, MS Cohen. 2000. Acquiring simultaneous EEG and functional MRI. Clin Neurophysiol 111, 1974-1980.

Goodin DS, MJ Aminoff. 1984. Does the interictal EEG have a role in the diagnosis of epilepsy. Lancet 1, 837-839.

Herin RA, PT Purinton, TF Fletcher. 1968. Electroencephalography in the unanaestetized dog. Anim J Vet Res 29, 329-336.

Homan RW, J Herman, P Purdy. 1987. Cerebral localization of international 10-20 system electrode placement. Electroen Clin Neurophysiol 55, 376-382.

Homma S, T Musha, Y Nakajima, Y Okamoto, S Blom, R Flink, KE Hagbarth, U Mostrom. 1994. Location of electric current sources in the human brain estimated by the dipole tracing method of the SSB (Scalp - Skull - Brain) head model. Electroen Clin Neurophysiol 91, 374-382.

Ichinose F, M Miyazaki, T Goto, H Takahashi, K Terui, Y Niimi, S Uezono, S Morita, H Yanagida. 1999. Electroencephalographic responses to the formalin test in rats. Pain 80, 251-256.

Intriligator J, J Polich. 1995 On the relationship between EEG and ERP variability. Int J Psychophysiol 20, 59-74.

Ives JR, A Rotenberg, R Poma, G Thut, A Pascual-Leone. 2006. Electroencephalographic recording during transcranical magnetic stimulation in humans and animals. Clin Neurophysiol 117, 18701875.

Jus A, K Jus. 1954. Elektroencefalografia. PZWL, Warszawa, Poland, Pp 9-20.

Kaiser DA. 2005. Basic principles of quantitative EEG. J Adult Dev 12, 99-104.

Kalita J, UK Misra. 2006. EEG in dengue virus infection with neurological manifestations: A clinical and CT / MRI correlation. Clin Neurophysiol 117, 2252-2256.

Kayama Y. 2003. Ascending reticular activating system revisited: functional roles of cholinergic and monoaminergic projections from the brainstem. Workshop 20. Pharmacological aspects of EEG. Neurophysiology Posters WS-20-3.

Klass DW. 1977. Symposium on EEG montages: which, when, why and whither. Introduction. Am J EEG Technol 17, 1-3.

Konareva IN. 2005. Modifications of the EEG frequency pattern in humans related to a single neurofeedback session. Neurophysiol 37, 443-451.
Kowalczyk M, O Antkowiak. 2004. Influence of midazolam on somaninduced convulsive activity. Neurophysiology Posters Sessions P-56-7.

Kozelka JW, TA Pedley. 1990. Beta and mu rhythms. J Clin Neurophysiol 7 , 191-208.

Lesser RP, H Lueders, DS Dinner, H Morris. 1985. An introduction to the basic concepts of polarity and localization. J Clin Neurophysiol 2, 45-61.

LeVan P, E Urrestarazu, J Gotman. 2006. A system form automatic artifact removal in ictal scalp EEG based on independent component analysis and Bayesian classification. Clin Neurophysiol 117, 912-927.

Liporace J, W Tatum IV, GL Morris III, J French. 1998. Clinical utility of sleep-deprived versus computer-assisted ambulatory 16-channel EEG in epilepsy patients: a multi-center study. Epilepsy Res 32, 357-362.

Mahla ME. 1997. The electroencephalogram in the operating room. Semin Anesth 16, 3-13.

Marrosu F, F Santoni, M Puligheddu, L Barberini, A Maleci, F Ennas, M Mascia, G Zanetti, A Tuveri, G Biggio. 2005. Increase in $20-50 \mathrm{~Hz}$ (gamma frequencies) power spectrum and synchronization after chronic vagal nerve stimulation. Clin Neurophysiol 116, 2026-2036.

Mattia D, M Mattiocco, A Timperi, S Salinari, MG Marciani, F Babiloni, C Febo. 2004. Estimation of cortical activity from noninvasive highresolution EEG recordings. International Congress Series 1270, 245-248.

Millett D, H Berger. 2001. From Psychic energy to the EEG. Perspect Biol Med 44, 522-542.

Mumford H, JR Wetherell. 2001. A simple method for measuring EEG in freely moving guinea pigs. J Neurosci Meth 107, 125-130

Nishida S, M Nakamura, A Ikeda, H Shibasaki. 1999. Signal separation of background EEG and spike by using morphological filter. Med Eng Phys 21, 601-608.

Nowicki B, S Jasek, J Maciejowski, P Nowakowski, E Pawlina. 2001. Rasy zwierzat gospodarskich. PWN, Warszawa, Poland, Pp 66-69.

Nuncz PL. 1981. Electric fields of the brain: The neurophysics of EEG. Oxford University Press, New York, USA.

Nuwer MR. 2003. Clinical use of QEEG. Clin Neurophysiol 114 2294-2306.

Otsubo H, A Ochi, R Sakamoto, K Iida. 2004. Dipole source localization of epileptic discharges in EEG and MEG. International Congress Series 1270, 56-60.

Pampiglione G. 1963. The electrical activity of the brain in the young dog. Neurological and EEG correlative studies in infancy. Grune and Stratton, New York, USA, Pp 177-185.

Pellegrino F, M Etchepareborda. 1997. Anatomical sites for the placement of electroencephalographic record electrodes in canines. J Morphol Sci 14, 197-204.

Pellegrino FC, REP Sica. 2004. Canine electroencephalographic recording technique: findings in normal and epileptic dogs. Clin Neurophysiol 115, 477-487.

Razoumnikova OM. 2003. Reflection of the intelligence structure in the spatiotemporal features of the baseline EEG. Human Physiology 29, 619-626.

Reardon KA, IE Scheffer, LJ Smith, D Jolley, MK Horne. 1999. How long should a routine EEG be? J Clin Neurosci 6, 492-493.

Rosenblatt B, J Gotman. 1999. Computerized EEG Monitoring. Semin Pediatr Neurol 6, 120-127.

Rowan AJ, E Tolunsky. 2004. Primer of EEG With a Mini-Atlas. Elsevier Science, Copyright for the Polish edition by Wydawnictwo Medyczne Urban \& Partner,Wrocław, Poland.

Saito T, Y Watanabe, T Nemoto, E Kasuya, R Sakumoto. 2005. Radiotelemetry recording of electroencephalogram in piglets during test. Physiol Beh 84, 725-731.

Salansky N, A Fedotchev, A Bondar. 1998. Responses of the nervous system to low frequency stimulation and EEG rhythms: Clinical implications. Neurosci Biobehav R 22, 395-409. 
Shimegi S, T Ichikawa, T Akasaki, H Sato. 1999. Temporal characteristics of response integration evoked by multiple whisker stimulations in the barrel cortex of rats. J Neurosci 19, 10164-10175.

Susuki M, K Toyosawa, K Sitizyo, R Tatelaki, H Matsumoto, M Yoshida. 1985. Fundamental studies on clinical EEG in dogs. EEG and EcoG Bull Fac Agricultural Tohori University 37, 26-37.

Vaughan TM, LA Miner, DJ McFarland, JR Wolpaw. 1998. EEG-based communication: analysis of concurrent EMG activity. Electroen Clin Neurophysiol 107, 428-433.

Velis DN. 2005. Proposal for electroencephalogram standardization in aircrew selection. Epilepsy Behav 6, 27-30.

Vock J, P Achermann, M Bischof, M Milanova, C Müller, A Nirkko, C Roth, C Bassetti. 2002. Evolution of sleep and sleep EEG after hemispheric stroke. J Sleep Res 11, 331-338.

Weiergräber M, M Henry, J Hescheler, N Smyth, T Schnider. 2005. Electrocorticographic and deep intracerebral EEG recording in mice using a telemetry system. Brain Res Protoc 14, 154-164.
Wolpaw JR, N Birbaumer, DJ McFarland, G Pfurtscheller, TM Vaughan. 2002. Brain-computer interfaces for communications and control. Clin Neurophysiol 113, 767-791.

Wypych M, A Wróbel. 2004. Identyfikacja stanu funkcjonalnego mózgu przy pomocy nowych metod potencjałów wywołanych. Konferencja Nowe metody w neurologii 12, 49-55.

Yamagouchi N. 2000. Electrophysiological analysis of the effects of psychological drugs on the animal EEG. Workshop 20. Pharmacological aspects of EEG. Neurophysiology Posters WS-20-2.

Yoshida H, Z Peterfi, F García-García, R Kirkpatrick, T Yasuda, JM Krueger. 2004. State-specific asymmetries in EEG slow wave activity induced by local applications of TNFo. Brain Res 1009, 129-136.

Yoshinaga H, T Nakahori, K Kobayashi, Y Ohtsuka, E Oka, Y Kitamura, H Kiriyama, K Kinugasa, K Miyamoto. 2002. Benefit of combined use of EEG and MEG dipole. International Congress Series 1232, 419-426.

Zadra AL, TA Nielsen. 1998. Topographical EEG mapping in case of recurrent sleep terrors. Dreaming 8, 67-74. 